Laser Chem., 1999, Vol. 19, pp. 385-387 Reprints available directly from the publisher Photocopying permitted by license only
(C) 1999 OPA (Overseas Publishers Association) N.V. Published by license under the Harwood Academic Publishers imprint, part of The Gordon and Breach Publishing Group.

\title{
VIBRATIONAL MODE COUPLING TO REVERSE ELECTRON TRANSFER IN $(\mathrm{CN})_{5} \mathrm{FeCNRu}\left(\mathrm{NH}_{3}\right)_{5}^{-}$IN SOLUTION
}

\author{
CHENGFEI WANG, BORIS AKHREMITCHEV \\ and GILBERT C. WALKER* \\ Department of Chemistry, University of Pittsburgh, \\ Pittsburgh, PA 15260 USA
}

(Received 7 April 1997)

\begin{abstract}
We present charge transfer absorption, resonance Raman and time-resolved infrared spectral data for $(\mathrm{CN})_{5} \mathrm{FeCNRu}\left(\mathrm{NH}_{3}\right)_{5}^{-}$in various solvents. The transient infrared spectra and anisotropies reveal both non-equilibrium vibrational populations of high frequency modes and local solvent heating.
\end{abstract}

Keywords: Electron transfer; resonance Raman; infrared spectra; transient spectra

The static CT (electronic) absorption spectra (peak frequency and width) of $(\mathrm{CN})_{5} \mathrm{FeCNRu}\left(\mathrm{NH}_{3}\right)_{5}^{-}$in various solvents are strongly solvent coupled. Analysis of the bands indicates that $\mathrm{H}_{\mathrm{AB}}$ (electronic mixing) is large, but not strongly solvent dependent. The static IR spectra lead us to conclude that the trans-CN stretch (found at ca $2018 \mathrm{~cm}^{-1}$ in $\mathrm{D}_{2} \mathrm{O}$ ), which exhibits strong intensity, is strongly solvent coupled, and shifts to higher frequency with stronger H-bonding $\left(N\right.$-methylformamide $v s$. Formamide $\left.v s . \mathrm{D}_{2} \mathrm{O}\right)$. On the other hand, the cis-CN (found at ca $2047 \mathrm{~cm}^{-1}$ in $\mathrm{D}_{2} \mathrm{O}$ ), which exhibits strong intensity, is sharp, and not strongly solvent dependent. The bridging-CN exhibits weak intensity, is sharp and not strongly solvent coupled.

\footnotetext{
* Corresponding author.
} 
We have also collected static resonance Raman spectra CT band. The cis-CN stretch was not observed. The trans-CN was observed, but the intensity was strongly solvent dependent. The bridge-CN stretch exhibited large intensity, a modest solvent effect, and a small frequency shift.

The transient IR spectra seen in Figure 1 may be summarized as follows: Within $1 \mathrm{ps}$ there is a strong bleach of cis- $\mathrm{CN}$, a strong induced absorbance of trans-CN, which is shifted to lower frequency. With a ca 6 picosecond 1/e time there is decay of trans-CN induced absorbance, and an associated shifting to higher frequency. Also with about a $6 \mathrm{ps} 1 / e$ time, there is recovery of cis-CN bleach.

The electron transfer occurs in ca $100 \mathrm{fs}$ [1]. Therefore, we interpret these transient IR data in $\mathrm{D}_{2} \mathrm{O}$ as follows: Solvent heating induces principal spectral changes. The extent of early time frequency shift suggests $\mathrm{H}$-bond breaking and subsequent reforming at trans-CN. The transient IR data also show evidence of non-equilibrium vibrational states induced by the electron transfer process itself. We have simulated these states from the resonance Raman and static IR spectra [2].

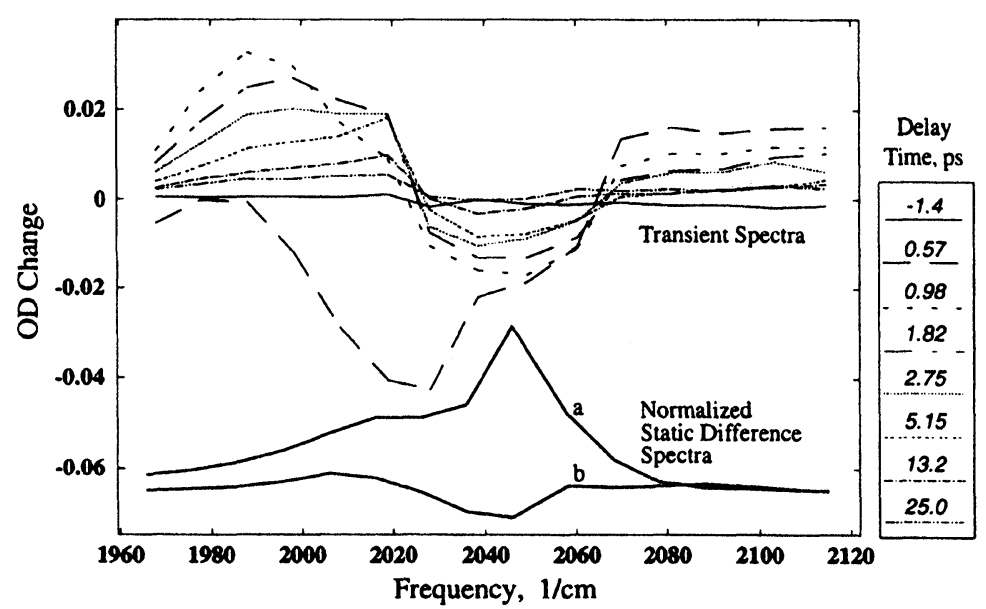

FIGURE 1 Fe-Ru in $\mathrm{D}_{2} \mathrm{O}$. Top: Transient IR spectra at various delay times. Bottom: $a$, solution minus $\mathrm{D}_{2} \mathrm{O}$ difference spectrum; $\mathrm{b}$, further difference spectrum, $90^{\circ} \mathrm{C}$ minus $26^{\circ} \mathrm{C}$. 


\section{References}

[1] Tominaga, K., Kliner, D. A. V., Johnson, A. E., Levinger, N. E. and Barbara, P. F. (1993). J. Chem. Phys., 98, 1228.

[2] Myers, A. B. (1996). Chem. Rev., 96, 911. 